\title{
Pengaruh Kedisiplinan Terhadap Kinerja Karyawan Pada PT. Bhakti Karya Distribusi Indonesia
}

\author{
Zackharia Rialmi \\ Dosen Fakultas Ekonomi Universitas Pamulang \\ Email : dosen02153@unpam.ac.id
}

\begin{abstract}
ABSTRAK
Tujuan pada penelitian ini adalah untuk mengetahui pengaruh kedisiplinan terhadap kinerja karyawan pada PT. Bhakti Karya Distribusi Indonesia.

Metode yang digunakan adalah metode deskriptif dengan pendekatan asosiatif. Teknik sampling yang digunakan adalah proporsional random sampling menggunakan metode teknik sampling jenuh dengan sampel sebanyak 80 responden. Analisis data menggunakan analisis regresi, analisis koefisien korelasi, analisis koefisien determinasi dan uji hipotesis.

Hasil penelitian kedisiplinan pada PT. Bhakti Karya Distribusi Indonesia dengan 10 pernyataan, memberikan jawaban yang bervariasi. Indikator teladan pimpinan diperoleh skor sebesar 3,74, indikator ketegasan skor sebesar 3,82, indikator keadilan skor 3,86, sedangkan indikator sanksi dan hukuman skor sebesar 3,79. Secara keseluruhan skor rata-rata dari empat indikator termasuk pada rentang skala 3,40-4,19 dengan kriteria baik. Kinerja karyawan pada PT. Bhakti Karya Distribusi Indonesia, responden, memberikan jawaban yang bervariasi. Indikator kuantitas skor sebesar 3,83, indikator kualitas skor sebesar 3,94, indikator ketepatan waktu rata-rata skor 4,00, sedangkan indikator efektifitas skor rata-rata sebesar 3,83. Secara keseluruhan skor rata-rata dari lima indikator termasuk pada rentang skala 3,40-4,19 dengan kriteria baik. Terdapat pengaruh positif dan signifikan kedisiplinan terhadap kinerja karyawan dengan kontribusi pengaruh sebesar 0,577 atau $57,7 \%$ sedangkan sisanya sebesar $42,3 \%$ dipengaruhi faktor lain. Uji hipotesis diperoleh $\mathrm{t}$ hitung $>\mathrm{t}$ table atau $(10,319>1,991)$ dengan demikian $\mathrm{H}_{0}$ ditolak dan $\mathrm{H}_{1}$ diterima artinya terdapat pengaruh positif dan signifikan antara kedisiplinan terhadap kinerja karyawan.
\end{abstract}

Kata Kunci: Kedisiplinan dan Kinerja Karyawan. 


\section{PENDAHULUAN}

SDM (sumber daya manusia) adalah salah satu faktor yang sangat penting bahkan tidak dapat dilepaskan dari sebuah organisasi, baik institusi maupun perusahaan. SDM juga merupakan kunci yang menentukan perkembangan perusahaan. Pada hakikatnya, SDM berupa manusia yang dipekerjakan di sebuah organisasi sebagai penggerak, pemikir dan perencana untuk mencapai tujuan organisasi itu. perkembangan terbaru memandang karyawan bukan sebagai sumber daya belaka, melainkan lebih berupa modal atau aset bagi institusi atau organisasi. Hal ini dibuktikan dengan bergesernya istilah HR (Human Resources) menjadi HC (Human Capital). Di sini SDM dilihat bukan sekadar sebagai sumber daya, tetapi modal yang bernilai dan dapat dilipatgandakan. Di sini perspektif SDM sebagai investasi bagi institusi atau organisasi lebih mengemuka. Secara garis besar, pengertian sumber daya manusia adalah individu yang bekerja sebagai penggerak suatu organisasi, baik institusi maupun perusahaan dan berfungsi sebagai aset yang harus dilatih dan dikembangkan kemampuannya.

Kedisiplinan atau displin adalah kesadaran dan kesediaan seseorang mentaati semua peraturan perusahaan, badan atau organisasi dan norma-norma sosial yang berlaku. Adanya tingkat disiplin kerja yang baik mencerminkan kredibilitas karyawan mencapai suatu hasil kerja yang optimal untuk kesuksesan perusahaan menurut Hasibuan (2013:193-194). Peningkatan kinerja kayawan juga dapat dilakukan dengan cara menciptakan disiplin kerja, karena disiplin kerja yang dikelola dengan baik akan menghasilkan kepatuhan karyawan terhadap berbagai peraturan organisasi yang bertujuan meningkatkan kinerja. Untuk itu pimpinan perusahaan perlu mengawasi setiap perilaku maupun tindakan yang dilakukan oleh seluruh karyawan pada saat bekerja.

Rendahnya kedisplinan karyawan pada PT Bhakti Karya Distribusi-Indonesia dapat dilihat dari data sesuai dengan tabel berikut ini :

Tabel 1

Data Absensi Karyawan PT Bhakti Karya Distribusi Indonesia Periode

\begin{tabular}{|c|c|c|c|c|c|c|c|}
\hline \multirow{2}{*}{ No } & \multirow{2}{*}{ Bulan } & \multirow{2}{*}{$\begin{array}{c}\text { Jumlah } \\
\text { Karyawan }\end{array}$} & \multirow{2}{*}{$\begin{array}{c}\text { Jumlah } \\
\text { Hari Kerja }\end{array}$} & \multicolumn{3}{|c|}{ Absensi } & \multirow{2}{*}{$\begin{array}{l}\text { Persentase } \\
\text { Kehadiran }\end{array}$} \\
\hline & & & & Sakit & Izin & Alpa & \\
\hline 1 & Januari & 80 & 26 & 27 & 3 & 13 & $57 \%$ \\
\hline 2 & Februari & 80 & 26 & 10 & 2 & 5 & $83 \%$ \\
\hline 3 & Maret & 80 & 26 & 15 & 1 & 8 & $76 \%$ \\
\hline 4 & April & 80 & 26 & 17 & 2 & 9 & $72 \%$ \\
\hline 5 & Mei & 80 & 26 & 23 & 4 & 8 & $65 \%$ \\
\hline 6 & Juni & 80 & 26 & 15 & 3 & 4 & $78 \%$ \\
\hline 7 & Juli & 80 & 26 & 12 & 2 & 4 & $82 \%$ \\
\hline 8 & Agustus & 80 & 26 & 16 & 3 & 7 & $74 \%$ \\
\hline 9 & September & 80 & 26 & 20 & 9 & 14 & $57 \%$ \\
\hline 10 & Oktober & 80 & 26 & 23 & 6 & 16 & $55 \%$ \\
\hline 11 & November & 80 & 26 & 24 & 2 & 13 & $61 \%$ \\
\hline 12 & Desember & 80 & 26 & 20 & 6 & 12 & $62 \%$ \\
\hline
\end{tabular}

Sumber: HRD PT Bhakti Karya Distribusi Indonesia 
Dari data tabel di atas menunjukan bahwa tingkat kehadiran karyawan masih sangat kurang. Hal ini ditunjukan dengan masih banyaknya pekerja yang tidak hadir tanpa berita (113 kali) periode Januari - Desember 2018 yang tentu saja akan sangat mempengaruhi kinerja atau produktivitas perusahaan.

Kinerja pada umumnya adalah hasil kerja yang dicapai oleh seseorang atau kelompok orang dalam suatu organisasi, sesuai dengan wewenang dan tanggung jawab masing-masing dalam rangka upaya mencapai tujuan organisasi bersangkutan, secara legal tidak melanggar hukum dan sesuai dengan moral maupun etika Mathis dan Jackson, (2013:113). Setiap karyawan yang memiliki kinerja yang tinggi dan baik dapat berkontribusi untuk mencapai tujuan serta sasaransasaran yang telah ditetapkan oleh perusahaan. Kinerja yang tinggi dapat dibentuk dengan adanya kesadaran setiap pimpinan perusahaan untuk memberikan dukungan kepada karyawan berupa keikutsertaan pemimpin dalam memberikan arahan mengenai pekerjaan yang dilakukan oleh setiap karyawan, dengan demikian karyawan dapat lebih memahami mengenai tanggung jawab pekerjaan yang mereka lakukan. Selain itu susasana tempat kerja yang nyaman, pemberian motivasi, penciptaan disiplin kerja yang baik dan kompensasi yang sesuai kepada setiap karyawan, akan dapat meningkatkan semangat karyawan dalam bekerja. Dapat dikatakan semakin baik kinerja karyawan di perusahaan tersebut maka semakin mudah perusahaan mencapai tujuannya, dan sebaliknya apabila kinerja karyawan itu rendah maka semakin sulit perusahaan dalam mencapai tujuannya. Berikut ini adalah data penilaian kinerja karyawan PT Bhakti Karya Distribusi Indonesia.

Tabel 2

Penilaian Kinerja Karyawan PT Bhakti Karya Distribusi Indonesia

\begin{tabular}{|c|c|c|c|c|c|c|c|c|c|}
\hline Tahun & \multicolumn{3}{|c|}{2016} & \multicolumn{3}{|c|}{2017} & \multicolumn{3}{|c|}{2018} \\
\hline $\begin{array}{c}\text { Aspek } \\
\text { Penilai } \\
\text { an }\end{array}$ & Jumlah & $\begin{array}{c}\text { Persent } \\
\text { ase }\end{array}$ & $\begin{array}{c}\text { Target } \\
\text { Pencap } \\
\text { aian }\end{array}$ & Jumlah & $\begin{array}{c}\text { Perse } \\
\text { ntase }\end{array}$ & $\begin{array}{c}\text { Target } \\
\text { Pencap } \\
\text { aian }\end{array}$ & $\begin{array}{c}\text { Jumla } \\
\text { h }\end{array}$ & $\begin{array}{c}\text { Persent } \\
\text { ase }\end{array}$ & $\begin{array}{c}\text { Target } \\
\text { Pencap } \\
\text { aian }\end{array}$ \\
\hline $\begin{array}{c}\text { Sangat } \\
\text { baik }\end{array}$ & 12 & $15 \%$ & $70 \%$ & 9 & $10 \%$ & $70 \%$ & 7 & $7 \%$ & $70 \%$ \\
\hline Baik & 16 & $20 \%$ & $20 \%$ & 15 & $19 \%$ & $20 \%$ & 12 & $15 \%$ & $20 \%$ \\
\hline Cukup & 52 & $65 \%$ & $10 \%$ & 56 & $71 \%$ & $10 \%$ & 61 & $78 \%$ & $10 \%$ \\
\hline Jumlah & 80 & $100 \%$ & $100 \%$ & 80 & $100 \%$ & $100 \%$ & 80 & $100 \%$ & $100 \%$ \\
\hline
\end{tabular}

Sumber: HRD PT Bhakti Karya Distribusi Indonesia

Tabel diatas menunjukan bahwa dari tiga tahun terakhir kinerja karyawan semakin menurun. Oleh karena itu kedisiplinan sangat dibutuhkan karyawan, agar kinerja menjadi lebih baik dan tujuan perusahaan dapat tercapai.

PT Bhakti Karya Distribusi Indonesia merupakan perusahaan swasta yang dimiliki oleh perorangan dan dikelola oleh sebagian keluarga pemilik, yang didalamnya terdapat kurang lebih 40 instansi/cabang yang bergerak di bidang retail, dengan Visi " Menjadi Peritel \& Grosiran Pilihan Utama di Indonesia. PT Bhakti Karya Distribusi Indonesia (Bhakti Karya), merupakan salah satu perusahaan jenis minimarket hingga hypermarket yang bergerak dim bidang retail 
menjual kebutuhan bahan pokok sehari-hari, dengan kualitas tinggi dan harga yang relatif murah dibandingkan dengan perusahaan retail / modern store lainnya. Mulai beroperasi pada tahun 1987, dijalankan oleh Bapak H. Ahmad Syafei dan Ibu $\mathrm{Hj}$. Ati Rohayati selaku pendiri dan pemilik PT Bhakti Karya Distribusi Indonesia.

Dari observasi awal yang penulis lakukan, ditemukan adanya indikasi kurangnya kedisiplinan yang diterapkan oleh PT Bhakti KaryaDistribusi Indonesia yang ditunjukan. Masih banyaknya karyawan yang mangkir kerja, berkeliaran pada saat jam kerja, Tingkat keterlambatan karyawan yang cukup tinggi. Hasil wawancara HRD PT Bhakti KaryaDistribusi Indonesia, tingkat tidak masuk kerja karyawan PT BhaktiKarya Distribusi Indonesia sangat tinggi di setiap bulannya, sehingga mencapai total 378 kali. Keseluruhan total tidak masuk kerja tersebut diperoleh dari jumlah karyawan yang tidak masuk kerja di setiap harinya dan di jumlahkan pada setiap bulannya. Jumlah tidak masuk kerja atau alfa yang paling tinggi yaitu pada bulan Oktober hingga mencapai sebanyak 16 kali. Kemudian tingkat mangkir karena alasan tertentu atau izin mencapai total 43 orang, dan absen karena sakit sebanyak 222 orang selama setahun. Data tersebut memperlihatkan adanya pergerakan jumlah karyawan yang tidak masuk kerja dengan berbagai alasan atau izin pada tiap bulannya. Dengan demikian dapat disimpulkan bahwa tingkat kedisiplinan karyawan PT Bhakti Karya Distribusi Indonesia masih rendah.

\section{METODE PENELITIAN}

Penelitian ini dilaksanakan di PT Bhakti Karya Distribusi Indonesia yang beralamat di Jl. Abdul Wahab No. 05 Sawangan-Depok. Jenis penelitian yang digunakan adalah dengan menggunakan metode penelitian kuantitatif, teknik pengambilan sampel yang digunakan adalah teknik sample jenuh berjumlah 80 dari seluruh populasi. Pengujian data digunakan uji instrumen, uji regresi, uji koefisien determinasi dan uji hipotesis dengan uji $t$ dan uji $F$. Menggunakan software SPSS Versi 24

\section{HASIL PENELITIAN DAN PEMBAHASAN \\ 1. Analisis Regresi Linier Sederhana.}

Uji regresi ini dimaksudkan untuk mengetahui perubahan pada variabel dependen jika variabel independen mengalami perubahan. Dalam penelitian ini adalah kedisiplinan $(\mathrm{X})$ terhadap kinerja karyawan (Y) pada PT Bhakti Karya Distribusi Indonesia. Berikut ini hasil olahan data regresi dengan SPSS Versi 24 yang dapat dilihat pada tabel berikut ini :

Tabel 3

Hasil Pengolahan Data Regresi Liner Sederhana

Coefficients $^{a}$

Unstandar Standar dized dized

Coefficient Coeffici

$\mathrm{s}$

\begin{tabular}{|c|c|c|c|c|c|}
\hline \multirow[b]{2}{*}{ Model } & \multicolumn{2}{|c|}{$\mathrm{S}$} & ents & \multirow[b]{2}{*}{ T } & \\
\hline & B & $\begin{array}{l}\text { Std. } \\
\text { Error }\end{array}$ & Beta & & $\mathrm{Si}$ \\
\hline $\begin{array}{l}1 \text { (Consta } \\
\mathrm{nt})\end{array}$ & $\begin{array}{r}13, \\
659\end{array}$ & $\begin{array}{r}2,46 \\
8\end{array}$ & & $\begin{array}{r}5,5 \\
34\end{array}$ & $\begin{array}{l}0 \\
00\end{array}$ \\
\hline $\begin{array}{l}\text { Kedisipl } \\
\text { inan }(X)\end{array}$ & $\begin{array}{r}, 74 \\
1\end{array}$ & ,072 & ,760 & $\begin{array}{r}10, \\
319\end{array}$ & $\begin{array}{l}0 \\
00\end{array}$ \\
\hline
\end{tabular}

a. Dependent Variable: Kinerja Karyawan (Y)

Sumber: Data Primer (Diolah data kuesioner 2019). 
Berdasarkan pada tabel di atas, diperoleh persamaan regresi linier sederhana dalam penelitian ini adalah: $\mathrm{Y}=13,659+0,741 \mathrm{X}$. Maka dapat dijelaskan sebagai berikut:

a) Nilai konstanta sebesar 13,659 diartikan bahwa jika variabel kedisiplinan tidak ada maka telah terdapat kinerja karyawan sebesar 13,659. Konstanta bernilai positif artinya memiliki hubungan yang positif.

b) Nilai 0,741 diartikan apabila konstanta tetap dan tidak ada perubahan pada variabel lain, maka setiap perubahan 1 satuan pada variabel kedisiplinan akan mengakibatkan terjadinya perubahan pada kinerja karyawan sebesar 0,741 point.

c)

\section{Analisis Koefisien Korelasi.}

Analisis koefisien korelasi dipergunakan untuk mengetahui tingkat kekuatan hubungan atau pengaruh antara variabel disiplin kerja terhadap kinerja karyawan pada PT Bhakti Karya Distribusi Indonesia Adapun hasil pengolahan data dengan program SPSS Versi 24, yaitu sebagai berikut:

Tabel 4

Hasil Analisis Koefisien Korelasi Correlations $^{b}$

\begin{tabular}{|c|c|c|c|}
\hline & & $\begin{array}{l}\text { Kedisiplinan } \\
\text { (X) }\end{array}$ & $\begin{array}{c}\text { Kinerja } \\
\text { Karyawan } \\
(Y)\end{array}$ \\
\hline \multirow[t]{2}{*}{$\begin{array}{l}\text { Kedisiplinan } \\
(\mathrm{X})\end{array}$} & $\begin{array}{l}\text { Pearson } \\
\text { Correlation }\end{array}$ & 1 &, $760^{* *}$ \\
\hline & $\begin{array}{l}\text { Sig. }(2- \\
\text { tailed) }\end{array}$ & & ,000 \\
\hline \multirow{2}{*}{$\begin{array}{l}\text { Kinerja } \\
\text { Karyawan } \\
\text { (Y) }\end{array}$} & $\begin{array}{l}\text { Pearson } \\
\text { Correlation }\end{array}$ &, $760^{\star *}$ & 1 \\
\hline & $\begin{array}{l}\text { Sig. }(2- \\
\text { tailed) }\end{array}$ & ,000 & \\
\hline
\end{tabular}

Berdasarkan tabel di atas, diperoleh nilai koefisien korelasi (R) sebesar 0,760, dan sesuai dengan ketentuan maka dapat disimpulkan bahwa kedisiplinan (X) memiliki tingkat kekuatan pengaruh yang kuat terhadap kinerja karyawan (Y).

\section{Analisis Koefisien Determinasi.}

Analisis koefisien determinasi dipergunakan untuk mengukur besarnya pengaruh variabel independen terhadap dependen. Berikut ini hasil perhitungan koefisien determinasi yang diolah dengan program SPSS Versi 24, terlihat pada tabel bawah ini:

Tabel 5

Hasil Analisis Koefisien Determinasi Model Summary

\begin{tabular}{|c|c|c|c|c|}
\hline & & 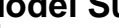 & yingary & \\
\hline Model & $\mathrm{R}$ & $\begin{array}{c}\mathrm{R} \\
\text { Square }\end{array}$ & $\begin{array}{c}\text { Adjusted } \\
\text { R } \\
\text { Square }\end{array}$ & $\begin{array}{l}\text { Std. } \\
\text { Error of } \\
\text { the } \\
\text { Estimate }\end{array}$ \\
\hline 1 &, $760^{a}$ &, 577 &, 572 & 2,325 \\
\hline a. Prec & ictors: & (Constar & t), Kedisip & $\operatorname{inan}(X)$ \\
\hline
\end{tabular}

Berdasarkan hasil uji pada tabel di atas, diperoleh nilai $R$ square (koefisien determinasi) sebesar 0,577 maka dapat disimpulkan bahwa kedisiplinan (X) berpengaruh terhadap kinerja karyawan (Y) sebesar 57,7\% sedangkan sisanya sebesar $42,3 \%$ dipengaruhi oleh faktor lain.

\section{Pengujian Hipotesis (Uji t $)$.}

Pengujian hipotesis dimaksudkan untuk menguji penerimaan dan penolakan dari rumusan hipotesis. Adapun rumusan hipotesis dalam penelitian ini adalah. Adapun 
rumusan hipotesis yang penulis buat adalah:

$\mathrm{H}_{0}: \rho=0$ Tidak terdapat pengaruh positif dan signifikan antara kedisiplinan terhadap kinerja karyawan.

$\mathrm{H}_{1}: \rho \neq 0$ Terdapat pengaruh positif dan signifikan antara kedisiplinan terhadap kinerja karyawan.

Dalam penelitian ini digunakan kriteria signifikansi 5\% $(0,05)$ dengan membandingkan $t$ hitung dengan $t$ tabel yaitu sebagai berikut:

(a) Jika $t_{\text {hitung }}<t_{\text {tabel }}$ : berarti $\mathrm{H}_{0}$ diterima dan $\mathrm{H}_{1}$ ditolak $(\alpha=5 \%)$

(b) Jika $t_{\text {hitung }}>t_{\text {tabel }}$ : berarti $\mathrm{H}_{0}$ ditolak dan $\mathrm{H}_{1}$ diterima $(\alpha=5 \%)$

Besarnya $t_{\text {tabel }}$ dicari dengan menggunakan rumus:

$\mathrm{df}=(\mathrm{n}-2$, maka diperoleh $(80-2)=$ 78 sehingga $t_{\text {tabel }}=1,991$.

Hasil pengolahan data dengan program SPSS Versi 24, sebagai berikut:

Tabel 6

Hasil Uji Hipotesis (Uji t) Coefficients $^{a}$

Unstandar Standar dized dized

Coefficient Coefficie

$\mathrm{S}$

Std.

\begin{tabular}{lr|r|r|r|r} 
& \multicolumn{1}{|c|}{$\begin{array}{c}\text { Std. } \\
\text { Err }\end{array}$} & & & Si \\
Model & \multicolumn{1}{c|}{ or } & Beta & \multicolumn{1}{c}{ T } & g. \\
\hline 1 (Consta & 13,6 & 2,4 & & 5,53 & 0 \\
nt) & 59 & 68 & & 4 & 00 \\
\hline Kedisipl &, 741 &, 07 &, 760 & 10,3 & 0 \\
inan (X) & & 2 & & 19 & 00 \\
\hline
\end{tabular}

a. Dependent Variable: Kinerja Karyawan (Y)

Sumber: Data Primer (Diolah data kuesioner 2019).

Berdasarkan tabel di atas diperoleh nilai $t_{\text {hitung }}>t_{\text {tabel }}$ atau $(10.319>1.991)$, hal itu juga diperkuat dengan signifikansi
$0,000<0,05$. Dengan demikian maka $\mathrm{H}_{0}$ ditolak dan $\mathrm{H}_{1}$ diterima, hal ini menunjukkan bahwa terdapat pengaruh positif dan signifikan antara kedisiplinan terhadap kinerja karyawan pada PT Bhakti Karya Distribusi Indonesia.

\section{KESIMPULAN DAN SARAN}

A. KESIMPULAN

1. Variabel kedisiplinan (X) pada PT Bhakti Karya Distribusi Indonesia, dari 80 responden dengan 10 pernyataan, memberikan jawaban yang beragam. Untuk indikator teladan pimpinan diperoleh ratarata skor sebesar 3,74 dengan responden yang menjawab sangat setuju dan setuju sebesar $62,9 \%$ sedangkan yang kurang setuju, tidak setuju dan sangat tidak setuju sebesar $\quad 37,1 \%$. Indikator ketegasan diperoleh rata-rata skor sebesar 3,82 yang menjawab sangat setuju dan setuju sebesar $64,6 \%$ sedangkan yang kurang setuju, tidak setuju dan sangat tidak setuju sebesar $35,4 \%$. Indikator keadilan diperoleh ratarata skor sebesar 3,86 yang menjawab sangat setuju dan setuju sebesar $68,8 \%$ sedangkan yang kurang setuju, tidak setuju dan sangat tidak setuju sebesar $31,3 \%$. Indikator sanksi dan hukuman diperoleh rata-rata skor sebesar 3,79 yang menjawab sangat setuju dan setuju sebesar $68,8 \%$ sedangkan yang kurang setuju, tidak setuju dan sangat tidak setuju sebesar $31,3 \%$.

2. Variabel kinerja karyawan, responden memberikan jawaban yang beragam. Untuk indikator kuantitas diperoleh rata-rata skor 
sebesar 3,83 responden yang menjawab sangat setuju dan setuju sebesar $67,5 \%$ sedangkan yang kurang setuju, tidak setuju dan sangat tidak setuju sebesar $32,5 \%$. Indikator kualitas diperoleh ratarata skor sebesar 3,94 responden yang menjawab sangat setuju dan setuju sebesar $73,8 \%$ sedangkan yang kurang setuju, tidak setuju dan sangat tidak setuju sebesar $26,3 \%$. Indikator ketepatan waktu diperoleh rata-rata skor sebesar 4,00 responden yang menjawab sangat setuju dan setuju sebesar $75,6 \%$ sedangkan yang kurang setuju, tidak setuju dan sangat tidak setuju sebesar 24,4\%. Indikator efektifitas diperoleh ratarata skor sebesar 3,83 responden yang menjawab sangat setuju dan setuju sebesar $75,6 \%$ sedangkan yang kurang setuju, tidak setuju dan sangat tidak setuju sebesar $24,4 \%$.

3. Terdapat pengaruh positif dan signifikan antara kedisiplinan terhadap kinerja karyawan dengan diperoleh persamaan regresi $\mathrm{Y}=$ $13,659+0,741 X$. Nilai konstanta sebesar 13,659 dan koefisien regresi 0,741 dimana koefisien regresi angkanya bernilai positif. Nilai koefisien korelasi sebesar 0,760 atau memiliki pengaruh yang kuat dan nilai koefisien determinasi sebesar 0,577 atau $57,7 \%$ sedangkan sisanya sebesar $(100 \%-57,7 \%)=42,3 \%$ dipengaruhi faktor lain. Uji hipotesis diperoleh $\mathrm{t}_{\text {hitung }}>\mathrm{t}_{\text {tabel }}$ atau $(10,319>1,991)$ dengan demikian $\mathrm{H}_{0}$ ditolak dan $\mathrm{H}_{1}$ diterima artinya terdapat pengaruh yang positif dan signifikan antara kedisiplinan terhadap kinerja karyawan pada PT Bhakti Karya Distribusi Indonesia

\section{B. SARAN}

1. Variabel kedisiplinan, indikator yang paling lemah adalah pada pernyataan nomor 2 yaitu pimpinan selalu datang lebih awal dari karyawan dimana hanya mencapai score 3,70, meskipun termasuk dalam kategori baik, namun mengingat masih ada responden yang kuang setuju, tidak setuju dan sangat tidak setuju sebesar $37,1 \%$ maka untuk lebih baik lagi perusahaan harus dapat memberikan tindakan tegas kepada setiap pimpinan dalam kerangka pencapaian tujuan organisasi yang maksimal.

2. Variabel kinerja karyawan, indikator yang paling lemah adalah pada pernyataan nomor 3 yaitu target pekerjaan dan tugas dari perusahaan dapat di penuhi oleh karyawan dengan baik dimana hanya mencapai score 3,70, meskipun termasuk dalam kategori baik, namun mengingat masih ada responden yang kuang setuju, tidak setuju dan sangat tidak setuju sebesar 32,5\% maka untuk lebih baik lagi perusahaan harus berani mendorong agar karyawan memiliki integritas dalam mencapai performa dan kemampuan kerja yang sebaikbaiknya agar kesemuanya dapat menunjang bidang pekerjaan masing-masing bagian kerja.

3. Pengaruh kedisiplinan terhadap kinerja karyawan sebesar $57,7 \%$, hal ini menunjukkan bahwa kondisi masing-masing variabel harus ditingkatkan secara signifikan. Oleh karenanya 
disarankan kepada penelitian berikutnya agar melakukan penelitian yang relevan dengan cara memperbaiki indikator yang masih tidak baik atau dengan menambah sub indikator pertanyaan dan jumlah responden penelitian. Disamping itu, bisa juga dilakukan dengan menambah jumlah variabel bebas yang sesuai.

\section{DAFTAR PUSTAKA}

Abdurrahmat Fathoni, "Manajemen Sumber Daya Manusia", Rineka Cipta, Bandung, 2013.

Anwar Prabu Mangukenegara, "Manajemen Sumber Daya Manusia", PT. Remaja Rosdakarya, bandung, 2013.

As'ad, "Ilmu Sumber Daya Manusia”, Indeks, Jakarta, 2014.

Edwin B Flippo, "Prinsip-Prinsip Sumber Daya Manusia”, Edisi ke Duabelas, Erlangga, Jakarta, 2011.

Gomes, "Manajemen Sumber Daya Manusia”, Andi Publisher, 2013.

Handoko, "Manajemen Personalia dan Sumberdaya Manusia", Edisi Kelima, BPFE UGM, Yogyakarta, 2014

Hasibuan, "Manajemen SUmber Daya Manusia", Haji Masagung, Jakarta, 2013.

Iqbal, Hasan, "Analisis Data Dengan Statistik”, Bumi Aksara, Jakarta, 2013.

Mathis dan Jackson, "Manajemen Sumber Daya Manusia', Salemba Empat, 2013.

Rialmi, Z., \& Morsen, M. (2020). Pengaruh Komunikasi Terhadap Kinerja Karyawan PT
Utama Metal Abadi. JENIUS, 3(2), 221-227.

Rialmi, Z. (2017). Pengaruh Keadilan Prosedural Yang Diterapkan Kepemimpinan Pegawai Dan Kepuasan Kerja Pegawai Terhadap Kinerja Dari Pegawai BPBD Provinsi Riau. Jurnal Mandiri: Ilmu Pengetahuan, Seni, dan Teknologi, 1(2), 353374.

Rivai, Veithzal, "Manajemen Sumber Daya Manusia Untuk Perusahaan", Raja Grafindo Persada, Jakarta, 2015.

Sedarmayanti. "Manajemen Sumber Daya Manusia, Reformasi Birokrasi dan Manajemen Pegawai Negeri Sipil", Cetakan Kelima, PT Refika Aditama, Bandung, 2013.

Sugiyono, "Metode Penelitian Kuantitatif Kualitatif dan $R$ \& $D$ ”, Penerbit CV. Alfabeta, Bandung, 2016.

Sunarsi, D. (2018). Pengaruh Gaya Kepemimpinan dan Disiplin Kerja Terhadap Kinerja Karyawan Pada CV. Usaha Mandiri Jakarta. JENIUS, 1(2). Sunarsi, D. (2018). Pengaruh Motivasi Dan Disiplin Terhadap Produktivitas Kerja Karyawan Pada PT. Nadi Suwarna Bumi. Jurnal Semarak, 1(1).

Sutrisno,Edy, "Sumber Daya Manusia”, PT. Gramedia, Surabaya, 2012.

Tohardi, "Pemahaman Praktis Manajemen Sumber Daya Manusia", Unversitas Tnjung Pura, Mandar Maju, Bandung, 2012. 